\title{
¿CUÁNDO NUESTRAS IMÁGENES DEJAN DE PERTENECERNOS? LA TENSIÓN ENTRE EL DERECHO A LA PROPIA IMAGEN Y LA LIBERTAD DE INFORMAR
}

\author{
WhEN DO OUR IMAGES STOP BELONGING TO US? THE TENSION BETWEEN
}

THE RIGHT TO ONE'S IMAGE AND THE LIBERTY OF THE PRESS

QUAND NOS IMAGES NE SONT PLUS À NOUS? LA TENSION ENTRE LE DROIT

À LA PROPRE IMAGE ET LA LIBERTÉ D'INFORMER

María José Arancibia Obrador ${ }^{*}$

\section{INTRODUCCIÓN}

La sentencia que a continuación comentaremos ${ }^{1}$ resulta sumamente interesante, pues es una de las primeras que se encarga de evaluar desde la perspectiva de los derechos de la personalidad la licitud de ciertas conductas que pueden desarrollarse en relación con elementos que forman hoy parte de nuestro diario vivir, como son las redes sociales, refiriéndose en particular al precario equilibrio que existe entre la exposición de ciertos aspectos de nuestra privada que a través de ellas se produce y el control último que el usuario conserva de ellas. Sobre esta base, el fallo se plantea la interrogante acerca de si es posible que terceros puedan hacer un uso libre de las fotografías que un usuario ha subido a su cuenta, sin contar con permiso alguno de su titular, respondiendo afirmativamente. Sin embargo, para arribar a su conclusión, en esta ocasión la Corte Suprema realiza una ponderación de derechos, que tal como veremos, deja algunos problemas que no satisfacen la interpretación sistemática de la ley. Finalmente, cabe destacar que ha sido precisamente en conocimiento de la acción constitucional de protección que ha correspondido a la Corte desarrollar una jurisprudencia en materia de derecho a la imagen de que cada persona es titular, sea en circunstancias que ella se ha afectado por medio del uso de una fotografía en que ella aparece retratada, por haberse utilizado su imagen para fines publicitarios, o que su imagen es usada en el contexto informativo de un reportaje, o como ocurre

*Abogada. Licenciada en Ciencias Jurídicas y Sociales por la Universidad Gabriela Mistral. Magíster (C) Universidad de Chile, Mención Derecho Privado. LLM en Economía y Finanzas, Universidad Gabriela Mistral. Profesora de Derecho Civil Facultad de Derecho de las Universidades Gabriela Mistral y Alberto Hurtado, Santiago, Chile. Correo electrónico: mariajose.arancibia@ugm.cl.

Agradezco los comentarios del profesor Pablo Cornejo Aguilera.

${ }^{1}$ Corte de Apelaciones de Valparaíso, "Raúl David Alvarado Granja contra Canal 13 S.A.”, 7 de julio de 2014 (recurso de protección), Rol No 1306-2014. Revocada por la Corte Suprema, 8 de octubre de 2014, Rol No 21499-2014. 
precisamente en este caso en particular, donde se emplean por un canal de televisión imágenes obtenidas desde la red social Facebook ${ }^{2}$.

\section{ANTECEDENTES DEL CASO}

En el caso que comentamos, los tribunales superiores de justicia son llamados a intervenir como consecuencia de un recurso de protección interpuesto por don Raúl David Alvarado Granja, pastor evangélico de la Iglesia Unida Metodista Pentecostal, en contra de Canal 13 S.A., representado legalmente por don Luis Hernán Browne. Según expone el recurrente, la conducta de la estación televisiva habría infringido sus derechos fundamentales, pues él habría otorgado una entrevista a personal de Canal 13, dentro del contexto de un reportaje-denuncia titulado "Indignados por ruidos molestos. Guerra entre vecinos e iglesia", siempre bajo la condición de que ésta no fuera grabada, por cuanto no quería que su imagen saliera al aire. Esta condición, según expone, fue aceptada por el periodista que hizo el reportaje y posteriormente sería incumplida por la estación, dado que la entrevista salió en definitiva al aire, y se encuentra en la página web de Canal 13, conteniendo imágenes de su persona, de su cónyuge y de un amigo, todas cuales habrían sido extraídas desde su Facebook personal, cuestión no autorizada por el recurrente.

En cuanto al derecho, el recurrente denuncia a la Corte que Canal 13 ha incurrido en un acto ilegal y arbitrario, al momento de exhibir fotografías en las que aparece tanto él como su cónyuge, imágenes que fueron obtenidas sin su consentimiento y contraviniendo las condiciones en que accedió a dar la entrevista, toda vez que expresamente se le señaló al periodista que lo entrevistó que no quería ser grabado por cuanto no deseaba que su imagen saliera al aire, todo esto en el marco de un reportaje a la Iglesia Evangélica de la cual es pastor. Por consiguiente, estima que se han vulnerado las garantías constitucionales de los numerales $4^{\circ}$ (protección de la vida privada) y $24^{\circ}$ (protección del derecho de su propia imagen, invocando formalmente la especie de propiedad que sobre él tendría) del artículo 19 de la Constitución Política de la República, ello por cuanto nunca otorgó su consentimiento para que Canal 13 use su imagen personal y la divulgue en forma indiscriminada a la audiencia televisiva.

\footnotetext{
${ }^{2}$ Corte Suprema, "Noelia Antonieta Araneda Velásquez, por los menores Nicolás Alexis Albornoz Araneda y Martín Vicente Moreno Jorquera en contra de Emilio José Castro Baeza, Víctor Adolfo Tapia Villa, Rodrigo Córdova Flores, Luis Silva Mieres, Elías Ulloa Vega y Fernando Cofré Monsalve”, 28 de enero de 2011 (recurso de protección), Rol No 9301-2010. Si bien este fallo fue conocido como el caso de "Castigo para todas esas personas que robaron en el Bigger de Yungay”, en dicha oportunidad se creó un grupo en esta red social en la cual se "subieron" fotografías de menores. Tiene relevancia en dos aspectos: en el primero de ellos, la Corte Suprema alude que al "subir" estas fotografías en las cuales se ven involucrados menores, no obstante estar en un espacio público no pierden sus derechos, y se ha vulnerado el artículo $19 \mathrm{No}_{\text {s. }} 1$ y 4 CPR. A pesar de haber alegado la parte recurrida que era su solo afán el de informar lo ocurrido en el lugar después del terremoto.
} 
Por su parte, Canal 13, estación televisiva recurrida, fundó sus defensas en cuestiones procesales, argumentando que la Corte de Apelaciones de Valparaíso era incompetente para conocer del recurso, puesto que la parte recurrida tiene su domicilio en Santiago, a lo cual agregó durante sus alegatos en estrados que su actuación se encuentra amparada en la Ley No $19.733^{3}$, sobre "Libertades de Opinión e Información y Ejercicio del Periodismo" y la garantía constitucional del artículo 19 No 12 de la Constitución Política de la República, consistente en la libertad de emitir opinión y de informar, sin censura previa. Finalmente, la recurrida argumentó que la petición estaba mal formulada, puesto que lo que debió haberse pedido era la eliminación de las imágenes.

\section{Argumentación de las Cortes}

Después de haber realizado esa breve introducción, destacando los antecedentes relevantes de la controversia, corresponde nos refiramos a los puntos más relevantes contenidos en la argumentación desarrollada en primera instancia por la Corte de Apelaciones de Valparaíso, y en segunda instancia por la Corte Suprema, los cuales analizaremos de forma más detallada en la sección siguiente.

En primera instancia, la Corte de Apelaciones de Valparaíso estuvo por acoger el recurso de protección en contra de Canal 13, ordenándole eliminar del reportaje emitido en el programa "Bienvenidos" de la página web del canal, las imágenes correspondientes a la persona del recurrente, Raúl David Alvarado Granja y demás imágenes obtenidas desde su Facebook personal, exponiendo en sus considerandos Octavo y Undécimo de su sentencia que ha quedado suficientemente acreditado en autos que la estación televisiva usó imágenes personales del recurrente y de su familia, sin contar con autorización para ello, acto arbitrario que afecta un atributo de la persona, susceptible de protección. En este sentido, recogeremos los señalados considerandos, por decir relación con el derecho a la propia imagen, donde la Corte señala:

"Octavo: Que de lo expuesto en el libelo del recurso de protección deducido como de la intervención del abogado representante de la recurrida en su alegato y de la revisión del C.D. por estos Ministros, ha quedado acreditado que en el reportaje cuestionado transmitido en el programa 'Bienvenidos' del Canal 13, se han usado imágenes personales del recurrente y de familiares, sin su autorización, antes de iniciarse la entrevista, perturbando el ejercicio de su derecho de propiedad sobre su propia imagen y la de su familia. En ningún momento ha otorgado autorización facultando al Canal para utilizar sus imágenes en el reportaje en cuestión, actuación que constituye una infracción constitucional, ya que la imagen corporal es un atributo de la persona y como tal, corresponde a cada individuo autorizar su

${ }^{3}$ Ley No 19.733, sobre Libertades de Opinión e Información y Ejercicio del Periodismo, Diario Oficial, 4 de junio de 2001. 
uso, constituyendo un derecho incorporal protegido por la Constitución Política de la República en el artículo 19 No $^{2} 4$ ".

[...]

"Undécimo: Que, a mayor abundamiento, y de acuerdo a los antecedentes expuestos por recurrente y recurrido, no cabe duda que de parte del Canal 13, entidad televisiva, cometió un acto arbitrario al incluir en el referido reportaje imágenes sacadas del Facebook del recurrente, en circunstancias, que expresamente no se había dado autorización para ello"s.

Sin embargo, este criterio no sería seguido por el máximo tribunal del país. La Corte Suprema, rechazando el criterio de la Corte de Apelaciones, al conocer de este recurso vía apelación, revocó la sentencia de primera instancia, por considerar que en la materia resultaba necesario realizar un ejercicio de ponderación entre los diversos derechos involucrados, considerando particularmente los efectos que su decisión podría tener con relación al ejercicio de la libertad de expresión y con el derecho al acceso a la información. De esta forma, la Corte en su decisión incluyó una mirada desde el interés público, lo cual la lleva a concluir que una vez publicadas de manera voluntaria las señaladas imágenes por su titular en una red social, abierta al público, no puede con posterioridad pretenderse una exclusividad sobre ellas. En este sentido, recogemos los argumentos expresados en los considerandos Cuarto, Sexto y Séptimo del fallo de la Excma. Corte, donde se señala:

"Cuarto: Que el citado derecho puede -como ocurre en la especie- entrar en colisión con otros derechos y particularmente con el ejercicio de la libertad de expresión y con el derecho de acceso a la información, de lo que se colige que no tiene un carácter absoluto y que, por ende, se encuentra sujeto a límites tales como el interés público en que la ciudadanía conozca de una determinada información".

$[\ldots]$

"Sexto: Que el ordenamiento jurídico nacional, específicamente en el artículo 30 de la Ley No 19.733, regula lo que debemos entender por 'interés público', preceptuando en su literal e) que se consideran como hechos de interés público de una persona: 'los acontecimientos o manifestaciones de que el interesado haya dejado testimonio en registros o archivos públicos". "Séptimo: Que, en la especie, al margen de cuál haya sido la finalidad con que fueran conseguidas, lo cierto es que las imágenes captadas del recurrente no se obtuvieron en forma subrepticia. Antes bien, se trata de imágenes que siempre estuvieron a disposición de quien quisiera verlas, en cuanto el actor las incorporó a su página del sitio de internet denominado Facebook sin ningún tipo de restricción en cuando a quienes pueden acceder a ella, por lo que una vez que las referidas fotografías fueron publicadas en una red social abierta al público no puede pretenderse una exclusividad sobre ellas, configurándose, en consecuencia, la existencia de un interés público real, el cual constituye-como ya se dijo- un limite expresamente reconocido por el legislador respecto del derecho constitucional a la propia imagen"s.

\footnotetext{
${ }^{4}$ Corte de Apelaciones de Valparaíso, 7 de julio de 2014, Rol No 1306-2014. Énfasis agregado.

${ }^{5}$ Corte Suprema, 8 de octubre de 2014, Rol No 21499-2014. Énfasis agregado.
} 
LA TENSIÓN ENTRE EL DERECHO A LA PROPIA IMAGEN Y LA LIBERTAD DE INFORMAR

Esta decisión no fue unánime. El fallo tuvo un voto en contra de la Ministro Sra. Egnem, quien estuvo por confirmar el fallo en alzada, teniendo para ello especialmente presente:

“(...) que el recurrente de buena fe accedió a la entrevista habiéndosele asegurado que no se grabaría su imagen, y no obstante ello se obtuvo su imagen de su página de Facebook $y$, sin su consentimiento, se la exhibió precisamente vinculada a la entrevista, acción que no puede sino considerarse arbitraria en cuanto cada persona tiene la facultad exclusiva de determinar no sólo la forma en que se capten imágenes de sí misma sino que también el modo y contexto en que éstas se reproducen y hacen públicas, motivo por el que quien disiente considera vulnerado el derecho a la privacidad y a la propia imagen del recurrente, consagrado en el artículo $4^{\circ}$ de la Carta Fundamental' 6 .

Como se puede apreciar de lo expuesto, la forma en que cada tribunal abordó la cuestión controvertida en el presente caso es diferente: mientras que la Corte de Apelaciones de Valparaíso centró su decisión en la ausencia de una autorización para efectos de configurar la afectación del derecho a la personalidad invocado, dando de esta forma mayor relevancia a la esfera negativa del derecho, cuyo objeto consiste precisamente en la facultad de excluir a otros del aprovechamiento de la propia imagen; la Corte Suprema centró el conflicto en la posible existencia de una colisión de derechos fundamentales, quedando la autorización como uno de los antecedentes a considerar en la labor de ponderación, permitiendo de esa forma considerar otros elementos que concurren en el conflicto y que permiten configurar excepciones a la esfera de protección del derecho invocado por la recurrente, como ocurre con el interés público.

Sin embargo, más allá de los méritos que pueda tener la decisión en alzada, al considerar en su decisión diversos derechos fundamentales en conflicto, nos parece que en esta segunda aproximación la Excma. Corte ha incurrido en ciertas imprecisiones al momento de efectuar la ponderación, que obligan a revisar la aplicabilidad de esta jurisprudencia a casos futuros, como veremos a continuación.

\section{Comentario de la SENTENCIA}

Como señalamos al inicio de este comentario, el recurrente interpuso su recurso de protección invocando la afectación de sus derechos a la protección de la vida privada (artículo 19 No 4 CPR) y a la propia imagen (a través de la propiedad, artículo 19 No 24 CPR) en que habría incurrido Canal 13 como consecuencia de su actuar arbitrario e ilegal, al momento de exponer de manera no consentida imágenes que forman parte de la vida familiar del recurrente.

El análisis realizado por la Corte de Apelaciones y la Corte Suprema difieren notoriamente. Mientras en primera instancia, conociendo del recurso de protec-

6 Ídem. 
ción, la Corte estudió la acción interpuesta y consideró que el acto alegado era arbitrario e ilegal desde desde la perspectiva del derecho de propiedad sobre su "propia imagen y la de su familia"(desechando amparar la situación a través de la garantía constitucional del artículo 19 No 4 CPR), por estimar que si la estación televisiva deseaba usar la imagen del recurrente debió existir una autorización previa para ello, con lo cual la Corte reconoce una primacía del aspecto negativo del derecho a la propia imagen, permitiendo en consecuencia a su titular negar su uso por parte de terceros ${ }^{7}$; la Corte Suprema, en cambio, analiza el problema desde la perspectiva de la existencia de una colisión de derechos, entre la propia imagen por una parte (sin subsumirla expresamente en ningún numeral), y la libertad de expresión y el derecho de acceso a la información, por otra.

Sobre esta base, el máximo tribunal señala que el derecho a la propia imagen no tiene un carácter de absoluto, pues su límite lo encotramos en lo que debemos entender por el "interés público" que reviste la noticia para la ciudadanía, el cual permite que en el caso concreto termine por prevalecer la libertad de expresión y el acceso a la información. De esta forma, la Excma. Corte resuelve que no existe una transgresión al derecho a la imagen, desde el momento que las fotografías del recurrente se encontraban en una red social abierta al público, de manera tal que su titular no puede invocar una exclusividad sobre ellas: al ser una red "abierta al público" cualquiera tiene acceso a ellas, de manera tal que las fotografías están en una especie de registro público. Este fallo, con todo, no es unánime, existiendo un voto en contra, el cual argumenta que en efecto hay una acto arbitrario e ilegal al utilizar las imágenes, pues transgrede el derecho a la privacidad contemplado en el artículo 19 No 4 CPR, con lo cual a juicio del ministro disidente debía concederse la protección, pero basada en un numeral distinto.

Para efectos de poder evaluar críticamente el fallo de la Excma. Corte, debemos considerar tres elementos que están presentes en su decisión: a) ¿Qué debemos entender por derecho a la propia imagen?; b) ¿Qué debemos entender por interés público y qué importancia tiene en un conflicto como el descrito?; y c) ¿Cuál es la relevancia de la conducta del titular, que ha "subido" las imágenes a las redes sociales? Cada una de ellas será objeto de un desarrollo por separado.

\subsection{Derecho a la propia imagen}

En primer término, para poder comprender adecuadamente en qué consiste el derecho a la propia imagen, debemos comenzar por determinar en términos generales en qué consiste la "imagen”. La palabra imagen proviene del latín imago, imaginis, y se encuentra definida en el Diccionario de la Real Academia como " $f$ -

\footnotetext{
${ }^{7}$ No obstante ello, en el fallo de la Corte de Apelaciones no se llega al extremo de afirmar la autonomía del derecho a la propia imagen, cuestión que resulta del propio arbitrio procesal que se está empleando, que obliga a subsumir la discusión en el artículo 19 No 24 CPR, invocando una afectación del derecho de propiedad sobre la propia imagen.
} 


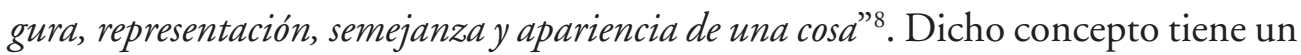
carácter amplio, que nos permite abarcar desde una persona hasta una cosa cuya representación quede plasmada en cualquier medio, como sería una fotografía o un video, entre otros. De esta manera, al hablar de la imagen estamos haciendo una referencia amplia, que abarca todos los elementos que caracterizan a una persona, los cuales pueden ir desde la voz, el rostro o el cuerpo, dado que cada uno de ellos es una proyección de la persona misma. Como señala Azurmendi, la imagen humana es una representación sensible, con lo cual se está haciendo hincapié en que la imagen no es una abstracción, sino una entidad concreta que tiene la cualidad de ser captada por los sentidos?.

Ahora bien, distinto es hablar del "derecho a la propia imagen", pues bajo este contexto, encontramos subyacentes dos derechos que lo componen: el primero que podríamos denominar negativo consiste en la facultad de impedir a cualquier tercero la posibilidad de reproducir sea total o parcialmente la imagen del titular del derecho, exigiendo como un requisito para que pueda hacerlo el contar con una autorización de su titular; y un segundo derecho sería en consecuencia positivo, el cual permite la utilización de la apariencia externa de aquello que lo hace reconocible. La existencia de estos dos derechos (o esferas dentro del derecho a la propia imagen) permite que el titular sea protegido frente a las posibles vulneraciones que provengan del actuar de terceros, pudiendo impetrar las acciones destinadas a protegerlo, a la vez que le reconoce las facultades para poder explotar su propia imagen.

Por todo lo expuesto, el derecho a la propia imagen se ha definido como aquel derecho que, teniendo el carácter de innato y perteneciendo a cada persona por el hecho de ser tal, se concreta en la reproducción o representación de la figura de ésta, en forma visible y recognoscible, confiriéndole un poder de control sobre ella; o mejor, como un poder estrictamente individual para disponer de la reproducción plástica de la propia fisonomía ${ }^{10}$.

Sin embargo, el derecho a la propia imagen carece de un reconocimiento expreso en nuestra legislación, a diferencia de lo ocurre en España ${ }^{11}$, por lo que, independientemente de su afirmación como un derecho de la personalidad por la doctrina civil, se trata de un derecho que no cuenta con un reconocimiento

${ }^{8}$ Diccionario de la Real Academia Española. Disponible en<http://lema.rae.es/drae/?val=imagen> [Consulta: 19 octubre 2014].

9 Azurmendi Adarraga, Ana (1997). El Derecho a la propia imagen: su identidad y aproximación al derecho a la información. Madrid: Editorial Civitas, pp. 24 y ss.

10 Arancibia Obrador, María José (2014). "Reflexionando sobre los derechos de la personalidad desde la perspectiva del derecho a la propia imagen". Revista de Derecho, Publicación de la Facultad de Derecho de la Universidad Católica del Uruguay, 2a Época, Año 9, No 9, julio, p. 65.

${ }^{11}$ Ley Orgánica 1/1982, de 5 de mayo, de protección civil del derecho al honor, a la intimidad personal y familiar y a la propia imagen. Disponible en: <https://www.boe.es/buscar/act.php?id=BOE-A-198211196\&tn=1\&vd=\&p=20100623\&acc=Elegir $>$ [Consulta: 29 octubre 2014]. 
autónomo dentro de nuestra Constitución, a diferencia de lo que ocurre con la vida privada y el honor (artículo 19 No $4 \mathrm{CPR}^{12}$ ). Es por esta razón que las discusiones que se han producido en nuestra jurisprudencia en sede de protección a propósito de este derecho no lo han tratado como un derecho autónomo ${ }^{13}$, siendo por el contrario habitualmente subsumido en otros derechos que sí están expresamente reconocidos en el catálogo del artículo 19 CPR, como son el honor y la privacidad, o bien derechamente reconociéndose que se ha vulnerado un derecho de propiedad que tiene cada uno sobre su propia imagen, de conformidad con el artículo 19 No 24 CPR.

Precisamente, en este caso y como bien lo ha entendido la Corte de Apelaciones de Valparaíso, al momento de exponer la estación de televisión públicamente imágenes que pertenecen a la vida privada de una persona, lo que está haciendo es afectar la esfera negativa del derecho, consistente en la facultad que tiene el titular de excluir a terceros en el uso de estas imágenes. Sin embargo, como se anticipa en la sentencia de la Excma. Corte, la utilización de la imagen de una persona puede traer diversas consecuencias y colocar en contraposición a otros derechos fundamentales como lo son la libertad de expresión, la libertad de informar y el acceso a la información (artículo 19 No $12^{14}$ ), cuando se trata de reportajes o noticias en las cuales se traten hechos de interés noticioso, sea que estén involucradas personas públicas o no, como ocurre en el caso de autos. En este contexto, lo relevante será definir cuándo el ejercicio de ponderación hará primar los segundos derechos sobre el primero, lo cual la Corte hace depender del "interés público". Por esta razón, corresponde que nos refiramos a este concepto.

\subsection{Interpretación del concepto "interés público"}

Como señalamos, resulta relevante detenerse en el análisis que realiza la Corte Suprema acerca de lo que debemos entender por “interés público" en el fallo, utilizado como límite para el derecho a la propia imagen, en beneficio de la libertad de expresión y el acceso a la información. Sobre este punto, resulta ilustrador

\footnotetext{
12 Artículo 19: "La Constitución asegura a todas las personas: No 4 El respeto y protección a la vida privada y a la honra de la persona y su familia".

13 Existen en doctrina autores que postulan la autonomía del derecho a la propia imagen. En Chile encontramos a Nogueira, para quien el derecho a la propia imagen es un derecho implícito en nuestra Constitución, institución jurídica reconocida tanto a nivel jurisprudencial como también doctrinaria, y en virtud de ello, es que se constituye como un derecho fundamental (tanto derecho constitucional como derecho humano). La afirmación anterior tiene por fundamento el artículo 29 literal c) de la Convención Americana de Derechos Humanos, que forma parte de nuestro ordenamiento jurídico interno vigente, como también el artículo $5^{\circ}$ inciso $2^{\circ}$ de nuestra Carta Magna. V. Nogueira Muñoz, Pablo (2010). El derecho a la propia imagen. Naturaleza Jurídica y sus aspectos protegidos. Santiago: Librotecnia, pp. 349-350.

${ }_{14}$ Artículo 19: "La Constitución asegura a todas las personas: No 12 La libertad de emitir opinión y la de informar, sin censura previa, en cualquier forma y por cualquier medio, sin perjuicio de responder de los delitos y abusos que se cometan en el ejercicio de estas libertades, en conformidad a la ley, la que deberá ser de quórum calificado".
} 
citar lo resuelto por la Corte Interamericana de Derechos Humanos, quien ha sostenido que "(...) en cuanto al carácter de interés público, en su jurisprudencia la Corte ha reafirmado la protección a la libertad de expresión respecto de las opiniones o informaciones sobre asuntos en los cuales la sociedad tiene un legitimo interés de mantenerse informada, de conocer lo que incide sobre el funcionamiento del Estado, o afecta derechos o intereses generales o le acarrea consecuencias importantes" 15 .

Este mismo criterio adopta el Tribunal Constitucional Español, quien se ha pronunciado en diversas ocasiones sobre conflictos entre los derechos comunicativos y los derechos al honor, a la intimidad y a la propia imagen, señalando también que en caso de colisión entre estos derechos habrá que ponderar los diversos intereses en conflicto, y en atención a los mismos determinar cuál de los derechos debe prevalecer ${ }^{16-17}$ : así, el Tribunal Constitucional Español ha reconocido a los derechos comunicativos una posición preeminente en el cuadro de los derechos fundamentales ${ }^{18}$, dado que su servicio a la causa de la creación de una opinión pública libre reviste a estos derechos de una fuerza particular en caso de colisión con otros derechos fundamentales, como la intimidad o la propia imagen, situándoles en una posición ventajosa de partida.

Esta prevalencia cobra todo su sentido cuando la información o la expresión recaen sobre asuntos de "interés publico". Así, las informaciones sobre asuntos de interés público quedarán muchas veces amparadas por el derecho a la información, aun cuando su difusión perjudique derechos de terceras personas implicadas en la misma, y ello porque se entiende oportuno sacrificar los bienes individuales -honor, intimidad o propia imagen, normalmente- en pro del bien colectivo: una sociedad correctamente informada de los asuntos de interés general. El interés público de ambos supuestos no tiene punto de comparación ${ }^{19}$.

Por su parte, la Excma. Corte, en la búsqueda de una interpretación al concepto de interés público, recurre a la Ley No 19.733 (conocida como Ley de Prensa), que en su artículo 30 regula lo que se debe entender por "interés público", disponiendo en su letra e) que se considera como hechos de interés público de una persona "los acontecimientos o manifestaciones de que el interesado haya dejado testimonio en

15 Corte Interamericana de Derechos Humanos, caso “Fontevecchia y D' Amico vs. Argentina”, sentencia de 29 de noviembre de 2011.

${ }^{16}$ Ponce Peñaranda, Consuelo; Martínez Otero, Juan y García Moliner, Lucía (2012). "La legitimidad jurídica y deontológica del uso de cámaras ocultas en periodismo". Revista Aranzadi de Derecho y Nuevas Tecnologías, septiembre-diciembre, No 30, p. 33.

17 SST 105/1990, de 6 de junio, caso José María García; 171 y 172/1990, de 12 de noviembre, relativas a un accidente de aviación y a su tratamiento por parte de los diarios El País y Diario 16; y 197/1991, de 17 de octubre, caso Sara Montiel.

${ }^{18}$ STC 165/1987, de 27 de octubre, E.J. 10 Afirmaciones similares pueden encontrarse en la jurisprudencia del TEDH, como por ejemplo, en las SSTEDH Thorgeir Thorgeirson c. Islandia, de 25 de junio de 1992, o Thomas c. Luxemburgo, de 29 de marzo de 2001

19 Ponce, Martínez y García (2012), pp. 21-43. 
registros o archivos públicos". Lo destacado en negrita es determinante, puesto que es lo que tuvo presente la Corte Suprema para rechazar el recurso de protección interpuesto por el Sr. Alvarado, por considerar que, como las fotografías se "subieron" a un red social, no preocupándose su titular de la cuenta de mejorar la privacidad, de manera tal que cualquiera puede ingresar y tener acceso a ellas, se daría este requisito por satisfecho. Así, considera la Corte Suprema que Facebook es una red social abierta al público, donde no existe exclusividad sobre las fotografías, y al ser "abierta al público" en dicho caso se cumple con lo dispuesto en la citada ley, pudiendo de esa forma construirse una limitación al derecho constitucional de la propia imagen, atendida la existencia de un "interés público".

Sin embargo, la posibilidad misma de recurrir a esta ley con la finalidad de definir el interés público no aparece como algo evidente. En este sentido, debemos hacer presente, tal como lo hace CovarRuBIAS, que la citada ley regula los delitos de injuria y calumnia, delitos típicos de lesión al honor y no al derecho a la intimidad ${ }^{20}-\mathrm{y}$ menos aún a la imagen-. Abonando a lo ya dicho, es la propia redacción del artículo 30 de la ley, al decir que "para lo dispuesto en el presente articulo se considerarán como hechos de interés público de una persona los siguientes", la que descarta su aplicación fuera del ámbito de ésta, dado que su interpretación no puede ser expansiva ni menos aún analógica, por corresponder a un párrafo que expresamente trata sobre delitos cometidos a través de un medio de comunicación social.

Por esta razón, más que buscar un criterio formal que permita definir la existencia de un "interés público" en casos como éste, lo relevante será atender a las circunstancias específicas que en él concurren, donde creemos que debe haber una diferencia entre un simple hecho "noticioso" y un "interés público informativo", siendo en este último caso donde nos encontramos dentro del ejercicio de la libertad de informar. No todo suceso, por el simple hecho que pueda tener un carácter de "noticioso", justifica una limitación a un derecho fundamental, máxime en circunstancias que, en la propia calificación del carácter "noticioso" de un hecho, puede tener un carácter determinante la decisión adoptada por el medio de comunicación social21 ${ }^{21}$.

Como un ejemplo de la utilización de este criterio, cabe citar al efecto el fallo recaído en el programa Enigma ${ }^{22}$, donde nos interesa destacar al efecto el considerando Sexto, donde la Corte resolvió "Que por medio del derecho a la intimidad, reserva o secreto, contenido en el art. $19 N^{\circ} 4$ de la Constitución, se reconoce la exis-

\footnotetext{
${ }^{20}$ Covarrubias Cuevas, Ignacio (2013). La vida privada de las figuras públicas. El interés público como argumento que legitima la intromisión en la vida privada. Santiago: LegalPublishing-Thomson Reuters, p. 172.

${ }^{21}$ Los medios de comunicación social en la actualidad no sólo persiguen la noticia, sino que además tienen un rol preponderante al fijar la agenda política.

22 Corte de Apelaciones de Santiago, "Alejandro M. Cuevas Arriagada; con Televisión Nacional de Chile; Productora de Televisión Nuevo Espacio", 30 de septiembre de 2003 (recurso de protección), Rol No 47432003. Confirmada por la Corte Suprema, 27 de octubre de 2003, Rol 4354-2003.
} 
tencia de una esfera privada en cada ser humano, constituida a menudo por sucesos de su vida afectiva, por defectos físicos o psíquicos, esfera relacionada con el pudor o con la utilización del tiempo del ocio, ámbitos en los cuales los individuos esperan encontrar respeto y comprensión, algún grado de serenidad y paz emocional. La existencia de una esfera privada implica el reconocimiento de actos públicos, que pueden $y$ deben ser conocidos por la ciudadanía toda, como son los actos de gobierno, las deliberaciones y acuerdos parlamentarios, las leyes que se hayan promulgado, las sentencias judiciales que se hayan dictado y algunos delitos de interés social. En virtud de estas consideraciones, parece incontestable que un robo con homicidio seguido de un delito de incendio, que son los hechos que el programa de televisión denominado 'Enigma' pensaba trasmitir, no quedan amparados por el derecho a la intimidad, reserva o secreto referido en este Considerando, y caen en la esfera pública" 23 .

A la luz de esta sentencia, podemos concluir que la Corte ha resuelto que estos actos de connotación pública dicen relación con el contenido de la libertad de informar, es decir estos actos sean de interés público informativo, siendo misión de la jurisprudencia a desarrollar el poder dotar de un contenido más preciso a este interés.

\subsection{Fotos publicadas en Facebook}

Finalmente, cabe nos refiramos a la importancia que tienen las redes sociales en el caso sometido al conocimiento de la Excma. Corte, para cuyos efectos resulta conveniente comenzar por explicitar qué entendemos por éstas: las redes sociales on line son aquellos servicios de la sociedad de la información que ofrecen a los usuarios una plataforma de comunicación a través de internet para que estos generen un perfil con sus datos personales, facilitando la creación de redes en base a criterios comunes y permitiendo la conexión e interacción con otros usuarios ${ }^{24}$, pudiendo distinguirse diversas clases de redes sociales: entre ellas podemos nombrar las redes sociales de comunicación ${ }^{25}$, las redes sociales especializadas ${ }^{26}$ y las redes sociales profesionales ${ }^{27}$. Para el caso que estamos comentando haremos referencia solamente a la primera, es decir, a las redes sociales de comunicación, que corresponden a aquellas plataformas donde los usuarios interactúan, proponen invitaciones a otros usuarios, publican fotografías, videos, reflexiones, noticias entre muchos otros datos que se van almacenando.

\footnotetext{
23 Ídem. Énfasis agregado.

${ }^{24}$ Ortiz López, Paula (2010). "Redes sociales: funcionamiento y tratamiento de información personal”. En: Derecho y Redes Sociales, Rallo Lombarte, Artemi y Martínez Martínez, Ricard (Coords.), Navarra: Thomson Reuters, Civitas, p. 22.

${ }^{25}$ Facebook, Google +.

${ }^{26}$ Genoom página cuya finalidad es realizar árboles genealógicos.

${ }^{27}$ LinkedIn.
} 
Teniendo claro lo anterior, debemos hacernos cargo de raciocino de la Corte Suprema, al indicar que por el solo hecho de estar estas fotografías en esta red social, de manera tal como se encuentran a la vista de todos son "públicas" y cualquiera puede hacer uso de ellas, se estaría consintiendo en el uso que otros puedan hacer de ellas. Sin embargo, para efectos de poder desarrollar esta idea, es necesario entender que uno al momento de abrir una cuenta en un red social (y en específico, Facebook) suscribe un contrato de adhesión, el cual incorpora una serie de derechos y de obligaciones que muchas veces no son considerados adecuadamente $-\mathrm{y}$ las más, no serán ni siquiera bien conocidos- por el usuario. Sin embargo, estos derechos y obligaciones miran a la relación entre el usuario y Facebook, quienes son las partes contratantes, lo cual implica, como consecuencia lógica del efecto relativo de los contratos, que en principio los terceros no puedan verse afectados por las señaladas disposiciones.

Como consecuencia de lo anterior, en aquellos casos en que una persona consienta que las fotografías sean publicadas en su "muro", solamente se está autorizando a la red social para realizar la señalada acción, sin que en ningún momento pueda extenderse de ese hecho una autorización para que terceros absolutos, que no tienen relación alguna con las partes, puedan aprovechar las imágenes que han sido dispuestas en la red social. Para comprobar la corrección de este análisis, desde la perspectiva del derecho a la propia imagen, baste considerar cuál sería nuestra respuesta a la siguiente interrogante: ¿ El hecho que "suba" una foto tomada en un destino turístico a mi perfil de Facebook, sin restringir las personas que pueden acceder a él, autoriza a una agencia de viajes a tomar la fotografía y utilizarla para comercializar su producto? A nuestro juicio, resulta manifiesta la respuesta negativa.

Ahora bien, ¿̨cuál es la importancia de esto, para casos como el de autos? Principalmente, ello nos permite decir que la sola publicación en redes sociales no puede implicar una autorización de uso por terceros, en la medida que se trate de una imagen protegida por el derecho a la propia imagen. Por el contrario, cualquier excepción deberá fundarse en una ponderación entre la libertad de información y este derecho, la que deberá ser resuelta conforme a criterios materiales, considerando en el caso concreto los antecedentes que permitan configurar la existencia de un interés público informativo, que considere en específico los beneficios que la revelación de esa información tendrán para el debate público y asumiendo correspondientemente la carga argumentativa que impone la limitación de la protección, sin que pueda llegar tampoco a decirse por analogía que la red social Facebook sea "un registro o archivo público" para efectos de la Ley No 19.733.

\section{REFLEXIÓN FINAL}

Creemos que el criterio utilizado por la Corte Suprema es en parte adecuado, pues dejó en claro que ningún derecho tiene el carácter de absoluto y se le reconoce límites, tal como lo señaló el fallo en comento. Lo que no compartimos 
es la manera como llegó al resultado, pues nos parece extremadamente peligroso que se legitime ampliamente el actuar de un tercero -en este caso de un canal de televisión- para poder obtener, "bajar" y utilizar de la cuenta de usuario de Facebook material fotográfico, por el solo hecho de existir un "interés público", máxime en circunstancias que su concurrencia en el caso concreto no es correctamente definido por la Excma. Corte, pudiendo incluso quedar subsumido en las decisiones que integran la línea editorial del canal. Sobre este punto, especialmente desaconsejable parece el recurrir a un criterio formal, como el contemplado en el artículo 30 letra e) de la Ley No19.733, sobre todo en circunstancias que ella parece ser una disposición que no está pensada para ser aplicada en un caso como el de autos, debiendo primar una interpretación según su contexto. Sin perjuicio de ello, creemos que el concepto de "interés público" es amplio, pero debe quedar circunscrito a hechos relevantes, que justifiquen verdaderamente una intromisión en la privacidad o una afectación de la propia imagen de la persona.

Precisamente, por esta razón es necesario construir una argumentación adecua$\mathrm{da}$, que sopese adecuadamente los intereses en conflicto, reconociendo, como lo señala el profesor Barros, que "la publicidad amenaza con exponer al público aquello que nos embaraza o avergüenza. Frente a los demás particulares, grados significativos de privacidad son condición para que podamos desplegar nuestra personalidad, en un equilibrio, por un lado, entre nuestro interés por guardar espacios de intimidad y, por otro, por poder comunicarnos sin restricciones con los demás" 28 .

Hoy vivimos en una sociedad que nos proporciona oportunidades de comunicación y descubrimiento que resultaban impensables hace tan solo algunos años, producto del espectacular desarrollo de la técnica. Sin embargo, la "sociedad de la información" no solamente implica estos beneficios, sino que también genera nuevos riesgos, derivados del hecho que nuestros datos suelen estar expuestos, posibilitando que terceros puedan entrar en nuestras vidas. Frente a esto, es necesario afirmar cuáles son los deberes de corrección que siempre debemos cumplir, incluso cuando actuamos desde lo digital. El tener una cuenta en una red social no autoriza per se el poder "tomar" de ella lo que plazca -imágenes o pensamientos-, debiendo imponerse siempre el respeto por los derechos fundamentales como un límite.

${ }_{28}$ Barros Bourie, Enrique (2006). Tratado de la Responsabilidad Extracontractual. Santiago: Editorial Jurídica de Chile, p. 545. 